http://jmscr.igmpublication.org/home/ ISSN (e)-2347-176x ISSN (p) 2455-0450

crossref DOI: https://dx.doi.org/10.18535/jmscr/v8i12.22

\author{
Journal Of Medical Science And Clinical Research \\ IGM Publication \\ An official Publication of IGM Publication
}

\title{
Case of COVID-19 Presenting as Ventricular Tachycardia
}

\author{
Authors

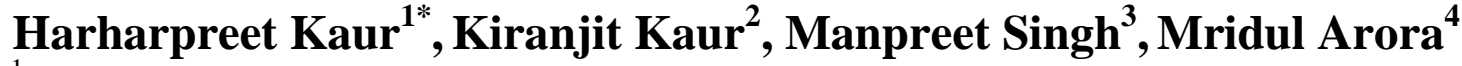 \\ ${ }^{1}$ Professor \& Head, Department of Medicine, MM Medical College, Kumarhatti, Solan \\ ${ }^{2}$ Professor, Department of Biochemistry, MM Medical College, Kumarhatti, Solan \\ ${ }^{3}$ Professor, Department of ENT, MM Medical College, Kumarhatti, Solan \\ ${ }^{4}$ Resident, Department of Medicine, MM Medical College, Kumarhatti, Solan \\ *Corresponding Author \\ Dr Harharpreet Kaur \\ Professor \& Head, Deptt of Medicine, MM Medical College, Kumarhatti, Distt. Solan, \\ Himachal Pradesh, India
}

\begin{abstract}
SARS-CoV- 2 primarily involves the lungs and causes respiratory symptoms. Concurrent cardiac complications have also been identified in COVID -19 infection. Cardiac injury can lead to arrhythmias by affecting the function of ion channels and cardiac action potentials. This injury may be an independent predictor for adverse outcomes. Our patient was an 82 year old male who presented with ventricular tachycardia. He was not a known cardiac patient. He did not have any clinical or ECG evidence of myocardial infarction nor any respiratory symptoms suggestive of COVID-19 infection. It could be a cardiac manifestation of COVID-19. All patients who present with clinical features suggestive of heart disease should be tested for COVID -19. Prompt recognition and treatment of arrhythmias may be lifesaving.

Keywords: COVID-19; Myocarditis; Ventricular tachycardia.
\end{abstract}

\section{Introduction}

Although clinical manifestations in patients with COVID- 19 are mainly related to the respiratory system, cardiovascular complications have also been identified. SARS- COV- 2 may induce apoptosis and myocardial damage secondary to hypoxia and myocarditis. It causes injury to cardiomyocytes which can affect the function of ion channels, action potential, and conduction abnormalities leading to cardiac arrhythmias. ${ }^{1}$

\section{Case Report}

Our patient was an 82 year old male who presented in the emergency department with deranged consciousness. There was no history of hypertension, diabetes or any previous heart disease. Though the patient used to experience occasional episodes of vague discomfort on severe exhertion he was not on any regular cardiac medication. He was a smoker but denied history alcohol consumption. He did not have any chest pain suggestive of acute myocardial infarction. There was no history of fever, cough or shortness of breath or any other symptom typical of a COVID-19 infection.

The patient was in shock with a systolic blood pressure of $70 \mathrm{~mm} \mathrm{Hg}$ on presentation.ECG showed ventricular tachycardia. (Figure 1) He was 


\section{JMSCR Vol||08||Issue||12||Page 132-134||December}

immediately cardioverted. The subsequent ECG did not show any changes suggestive of myocardial infarction. The patient regained consciousness and could walk around. His Trop T was negative. S creatinine was $2.9 \mathrm{mg} / \mathrm{dl}, \mathrm{S}$ potassium $4.36 \mathrm{meq} / \mathrm{L}$ and $\mathrm{S}$ sodium was
156meq/L. Other investigations were normal. He was tested for COVID-19 as a part of the hospital routine and found to be COVID positive. The second day the tachycardia recurred and the patient was referred to the cardiologist.

\section{Figure 1}

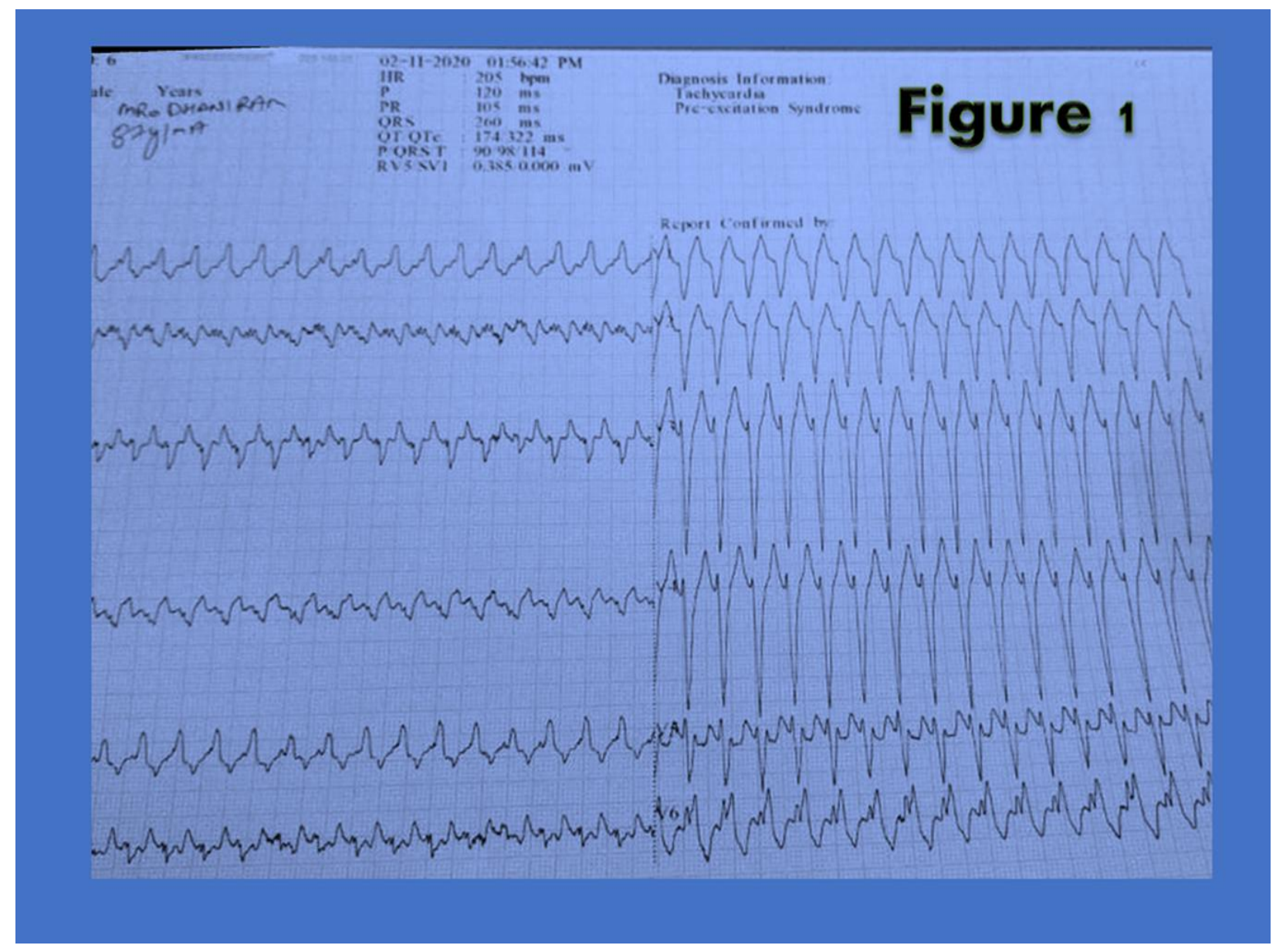

\section{Discussion}

COVID- 19- related cardiac arrhythmia was first described by Wang et al who reported a $17 \%$ (23/138) incidence of arrhythmias in these patients. ${ }^{2}$ Other reports indicated that only $26 \%$ of COVID-19 patients had normal ECGs and $33 \%$ of patients admitted to ICU developed arrhythmias. $60 \%$ of fatal cases of COVID- 19 succumbed to arrhythmias. ${ }^{1}$

The cardiac complications in patients with SARS- CoV- 2 infection have been attributed to abnormalities in cardiac structure and function including acute heart failure (HF), takotsubo syndrome, viral myocarditis and acute myocardial infarction. ${ }^{1}$ It was shown that elevated cardiac troponin I was an independent risk factor for COVID- 19 severity. ${ }^{3}$

COVID- 19 patients generally have comorbidities which can increase the risk of arrhythmias. Guo et al reported a $5.9 \%$ (11/187) incidence of malignant arrhythmias, including VT/ventricular fibrillation $(\mathrm{VF})^{4}$

Pro- inflammatory cytokines are usually increased in COVID- 19 patients, and cytokine storms have been reported in severe cases. Acute administration of IL- 6 significantly increased L- type $\mathrm{Ca} 2+$ current (ICaL) density in ventricular cardiomyocytes which resulted in 
changes in action potential and arrhythmias. ${ }^{5}$ Our patient had a normal Trop $T$. There was no evidence of myocardial infarction. The arrhythmia could have been a direct cardiac manifestation of COVID-19, myocarditis or myocardial damage secondary to hypoxia. Also it is possible that COVID infection caused exacerbation of a previously unidentified ischemia. The deranged renal function could be due to the effect of prolonged shock.

\section{Conclusion}

Thus COVID -19 can affect the heart and primarily present with a very serious arrhythmia. Arrhythmias should be regarded as one of the main complications of COVID- 19. All patients who present with cardiac manifestations should be tested for COVID -19 . Continuous electrocardiogram monitoring should be done routinely .Prompt recognition and treatment of arrhythmias may be lifesaving.

\section{References}

1. Wang et al Cardiac arrhythmias in patients with COVID- 19. Journal of Arrhythmia. 2020;36:827-836

2. Wang D, Hu B, Hu C, Zhu F, Liu X, Zhang J, et al. Clinical characteristics of 138 hospitalized patients with 2019 novel coronavirus- infected pneumonia in Wuhan, China. JAMA 2020;323(11):1061.

3. Chen C, Chen C, Yan J, Zhou N, Zhao JP, Wang DW. Analysis of myocardial injury in patients with COVID- 19 and association between concomitant cardiovascular diseases and severity of COVID- 19. Zhong Hua Xin Xue Guan Bing Za Zhi. 2020; 48: E008. https://doi.org/10.3760/cma.j.cn112148- 2 0200225- 00123
4. Guo T, Fan Y, Chen M, Wu X, Zhang L, $\mathrm{He} \mathrm{T}$, et al. Cardiovascular implications of fatal outcomes of patients with coronavirus disease 2019 (COVID- 19). JAMA Cardiol 2020;e201017.

5. Cao X. COVID- 19: immunopathology and its implications for therapy. Nat Rev Immunol. 2020;20(5):269-70. 